\title{
O fundamento do direito internacional na doutrina de Duguit - exposição e crítica
}

\author{
Moacyr Lobo da Costa
}

I. Léon Duguit, o decano de Bordeaux, elaborou uma teoria geral do direito, puramente objetiva, de cunho ciêntífico-positivista e radicalmente antimetafísica, cujos princípios espôs, de maneira magistral, no $1 .^{\circ}$ volume da $3 .^{a}$ ed. do monumental "traité de droit constitutionnel", lançada em 1927, um ano antes de sua morte.

Nessa obra Duguit condensou os princípios gerais de sua doutrina, que se encontravam difundidos e esparsos em várias publicações anteriores, notadamente "l'etat, le droit objetif et la loi positive", de 1901, "le droit social, le droit individuel et la transformation de l'État", de 1908, "les transformations générales du droit privé depuis le Code Napoléon" de 1912, "souveraineté et liberté", de 1921 e nas edições precedentes do "traité".

$\mathrm{Na}$ concepção ciêntífico-positiva do direito, partindo da observação dos fatos e só nos fatos procurando justificação para os fenômenos jurídicos, Duguit baniu, por considerá-las metafísicas e irreconsiliáveis com a realidade sociológica da vida jurídica, as noções de direito subjetivo e da personalidade jurídica dos grupos.

A sua doutrina tem por característico marcante a negação do direito subjetivo (individual e estatal), como um poder da vontade de se impôr às outras vontades; a negação sistemática da personalidade e da soberania, com os seus atributos de "dominium" e "imperium" segundo a acepção romana. 
Para Duguit, não existe o Estado, como entidade autônoma, como pessôa jurídica de direito público. Mas, apenas, governantes, isto é, homens que exercem o poder e impõem sua vontade aos governados, pela fôrça.

O Estado são os homens que governam. O poder mera questão de fato. Daí a negação da soberania como poder jurídico.

A soberania, como direito subjetivo do Estado é, para êle, uma noção metafísica, sem conteúdo real, assim como a personalidade jurídica do Estado. reitos.

Só o homem tem capacidade para o exercício dos di-

Só os homens que se encontram à testa do govêrno sâo titulares do poder de mando, que, apoiado pela fôrça, deve ser exercido de conformidade com as normas do direito objetivo.

A norma do direito objetivo, de formação espontânea, anterior e superior ao govêrno e que se impõe, igualmente, a todos os homens, governantes e governados, surge da solidariedade que entrelaça os homens, vivendo em sociedade, e do sentimento de justiça que a cimenta.

Duguit vai assentar nesses pressupostos doutrinários o fundamento do direito internacional.

No volume primeiro do "Traité" ( $3 .^{\mathrm{a}}$ ed.), nos parágrafos 17 e 67, êle explanou, pormenorizadamente, sua teoria sôbre o fundamento do direito internacional.

Sabe-se que, no momento em que a morte o colheu, Duguit se preparava para proferir uma série de conferências sôbre Direito Internacional, no Instituto de Altos Estudos Internacionais de Paris, nas quais, por certo, haveria de desenvolver, com o brilho costumeiro, os princípios fundamentais de sua doutrina e assentar as necessárias conclusões, com o que teria completado sua teoria a respeito dêsse importantíssimo ramo do direito. 
Na falta dêsses estudos, que seriam o coroamento de sua vasta obra de publicista, vejamos, então, segundo os ensinamentos reunidos no volume primeiro do "Traité", qual o fundamento do direito internacional.

\section{Exposição}

2. A seu ver, em determinadas situações, estabelecem-se relações entre os membros de dois ou mais grupos sociais, nitidamente diferenciados, relações essas que devem ser submetidas a uma norma. Esta norma, porém, se aplica ùnicamente aos membros dos dois grupos, considerados individualmente, e não aos grupos, tomados como tais e como constituindo entidades reais distintas dos indivíduos que os compõem.

Pois a norma visa às relações que se estabelecem entre os indivíduos e não entre os grupos.

Por outro lado, esta norma não pode ter por fundamento senão a consciência que os indivíduos componentes dos diferentes grupos têm da solidariedade que une não sòmente os membros de cada grupo, entre si, mas, também, os membros dos diferentes grupos uns com os outros.

Esta norma, de forma rudimentar, é uma norma econômica ou moral.

Existem, de fato, nas relações entre os membros dos vários grupos sociais, regras elementares, de que os indivíduos de cada grupo têm uma consciência mais ou menos nítida, das quais êles sentem a necessidade e às quais êles se submetem.

Essa é uma observação comprovada e indiscutível da sociologia.

Essas regras, econômicas ou morais, em determinadas circunstâncias podem se transformar em regras jurídicas intersociais.

A regra econômica, que regula as relações intersociais dos indivíduos componentes de grupos diferentes, transfor- 
ma-se em regra jurídica quando, na massa dos indivíduos dêsses grupos, se firma a consciência que a observância dessa regra é tão importante para as relações intersociais que a sanção da regra deve necessàriamente ser organizada e quando, ao mesmo tempo, se impõe à massa dos espíritos o sentimento da justiça dessa sanção.

Isto implica, evidentemente, que as relações entre os membros dos diferentes grupos são frequentes e duráveis, possibilitando o aparecimento dos sentimentos de sociabilidade e justiça que, elevados a um plano supra-individual, se transformam em sentimentos intersociais.

O sentimento que há uma interdependência estreita, não sòmente entre os membros de um mesmo grupo social, mas, também, entre os de grupos diferentes; o sentimento de justiça intersocial, isto é, que a justiça distributiva e a comutativa, sejam respeitadas igualmente no tratamento das relações dos indivíduos do mesmo grupo, como nas de grupos diferentes.

Quando, na massa dos indivíduos componentes de diferentes grupos se formou uma verdadèra consciência jurídica, a consciência que êles devem agir, uns em relação aos outros, segundo uma certa regra; que, se esta regra fôr violada, produzir-se-á, na massa dos indivíduos pertencentes a todos os grupos considerados, uma reação tendente a promover a sanção efetiva da violação; - surge, nêsse momento, a norma jurídica internacional.

Norma que tem por fundamento a consciência coletiva da solidariedade intersocial e da justiça da sanção contra os atos atentatórios ou violadores desta solidariedade.

A norma jurídica internacional tem, assim, por embrião a norma jurídica intersocial que, por sua vez, é um desenvolvimento da norma jurídica social, ou seja, da consciência da massa dos indivíduos que é justo o estabelecimento da sanção contra os atentados ou violações da solidariedade nas relações existentes entre indivíduos, seja de um mesmo grupo (norma social), seja de grupos diferentes (nor- 
mas intersociais) seja de grupos diferentes no plano internacional (normas internacionais).

Como a regra econômica ou moral, que é seu substratum, a norma jurídica é social, intersocial ou internacional por seu fundamento, mas individual em sua aplicação.

Ela não se aplica, nem se pode aplicar, aos grupos sociais, como tais, que não têm realidade pessoal, que não têm consciência nem vontade. Ela só se aplica aos indivíduos dêsses diferentes grupos, indivíduos entre os quais se estabeleceram as relações que demandam regulamentação.

Assim como em todo agrupamento social se impõe uma disciplina, que é o direito objetivo interno, assim, também, quando se formam liames de solidariedade entre indivíduos pertencentes a grupos diferentes, constitui-se, ao mesmo tempo, entre êles, um grupo intersocial que implica na existência de uma disciplina intersocial, ou seja, de uma norma objetiva de direito externo, o direito intersocial que é o embrião do direito internacional.

O fundamento de um direito internacional normativo aparece, assim, claramente.

Colocado sob êsse ponto de vista, fácil é afastar a objeção, comumente feita, que não pode haver um direito intersocial porque não existe um poder suprasocial para impor aos grupos subordinados uma lei superior.

A objeção desaparece se admitirmos que a regra de direito não é uma ordem imposta por uma vontade superior às vontades inferiores, mas, uma norma concebida como obrigatória e como devendo ser sancionada, que os indivíduos reconhecem e acatam antes mesmo dela vir a ser aplicada.

Se, de simples agrupamentos primários, com suas relações intersociais elementares, passarmos para o quadro das grandes coletividades, politicamente organizadas e diferenciadas, que se chamam Estados, a concepção do direito intersocial permanece verdadeira e válida. 
Liames de solidariedade unem, entre si, não sòmente os habitantes de um mesmo Estado, mas, também, os de Estados diferentes, e, sôbre o fundamento desta solidariedade firmam-se regras morais e econômicas que se aplicam às relações entre os membros dos diferentes Éstados.

Essas regras aplicam-se não aos Estados, considerados como pessôas de existência real e distinta da de seus membros individuais, mas, tão sòmente, aos individuos seus habitantes e fundamentam-se na consciência que têm êsses indivíduos que, se a elas não se submetessem, produzir-se-ia uma reação internacional que os constrangeria indiretamente a fazê-lo.

Essas regras morais e econômicas de ordem internacional aplicam-se a todos os membros de um grupo estatal e, de maneira tôda particular, aos governantes, isto é, aos indivíduos que detém o monopólio da fôrça dentro do agrupamento.

Pois são êles que mantêm as mais importantes relações intersociais que devem se subordinar às regras econômicas ou morais.

Ora, essas regras, em determinadas circunstâncias, podem se transformar em normas jurídicas e isso acontece quando, a massa dos espíritos compreende que, em razão da solidariedade internacional e da premente necessidade de justiça, é necessário que essas regras sejam sancionadas $\mathrm{e}$ as violações enèrgicamente reprimidas.

Esta concepção, e sòmente ela, servirá de fundamento para a regra interestatal.

É a consciência dos governantes e dos governados que, por suas manifestações dá a uma norma intersocial o caráter juridico.

É por que a massa dos espíritos está profundamente penetrada da idéia que, ao ser concluído um pacto entre os governantes de dois grupos nacionais distintos, seria perigoso para a solidariedade internacional e contrário ao sentimento de justiça que êsse pacto pudesse ser impunemente violado, é por essa razão que se formou a noção 
da regra jurídica internacional segundo a qual tôda convenção é obrigatória para os governantes que a concluiram.

A norma internacional, assim compreendida, como fundada na solidariedade internacional e no sentimento de justiça e aplicando-se, não a entidades imaginárias que seriam as nações e os Estados, mas aos indivíduos, governantes e governados que os compõem, afasta a objeção oposta à existência de um direito internacional pela inexistência de um poder de mando para impôr a norma aos diferentes Estados.

A fôrça obrigatória da norma jurídica não implica necessàriamente a existência de uma vontade superior impondo-se a uma vontade subordinada; ela implica, sòmente, na massa dos espíritos a consciência de seu caráter obrigatório.

A regra do direito internacional não implica a existência de um super-Estado para impôr sua vontade aos Estados subordinados; ela implica, sòmente, uma consciência jurídica internacional, isto é, a noção, na massa dos espíritos pertencentes a grupos estatais diferentes, que é justo seja uma determinada regra moral ou econômica enèrgicamente sancionada, pela fôrça, se necessário, pelo reconhecimento que o respeito dessa regra é indispensável à manutenção da solidariedade internacional.

Que a fôrça destinada a realizar esta sanção esteja ou não organizada, ou mesmo que não se possa organizá-la, pouco importa.

Há uma norma jurídica internacional no momento em que exista a consciência internacional de que tal regra deva ser respeitada, por ser êsse respeito justo e necessário à manutenção da solidariedade internacional.

Mas, objeta-se, êste direito internacional puramente normativo, admitindo-se que êle exista e que se possa fundá-lo sôbre essa consciência internacional, mais do que problemática, não é, verdadeiramente, um direito; tôda regra de direito é uma regra sancionada ou ao menos ga- 
rantida; a norma jurídica interna é acompanhada sempre de regras construtivas que determinam as vias de direito, no sentido geral da expressão, tendentes à sua realização; o direito normativo é sempre acompanhado do direito construtivo; ora, tal não se verifica nas relações intersociais, em geral, e particularmente nas relações interestatais.

Um direito internacional normativo pode existir; ou melhor, u'a moral internacional póde ser reconhecida, mas, um direito internacional construtivo não existe, nem pode ser concebido. Vias de direito, para sancionar as regras de direito internacional normativo, não podem ter existência prática.

Duguit responde à objeção invocando a Sociedade das Nações, formada em consequência do Tratado de Versailles, cuja missão precípua era garantir as normas do direito internacional, solenemente reconhecido, ante os reclamos da consciência jurídica dos povos civilizados e resolver os conflitos internacionais, impondo o respeito do direito internacional, não pela fôrça material de que a Sociedade não dispõe, mas pelo prestígio de sua autoridade e a grandeza mesma de sua missão.

$\mathrm{E}$ interroga - quê nos reserva o futuro? Ninguém o sabe; mas, é certo que, desde o presente, os povos civilizados se inclinam ante a supremacia do direito, embora não se tenha, ainda, constituído um organismo de coação para sancioná-lo diretamente.

Assim, ninguém deve desesperar do futuro.

Na evolução do grupo social, não foi senão lentamente que se organizaram as vias de direito e os meios de coação destinados a garantir a regra de direito que possibilitou a coexistência de fortes e fracos. Entretanto, a regra de direito existia antes que as vias de direito e os modos de coação fossem organizados.

Nas relações internacionais a mesma evolução parece se verificar.

Assim como, no direito interno, as normas precederam, de muito, as regras construtivas, destinadas a assegurar a 
sua efetividade e observância por meio da coação social, assim, também, o direito internacional, puramente normativo, no presente, caminha, através de peníveis esforços, para se tornar um direito construtivo, ou seja, no futuro, um direito internacional cujas normas sejam garantidas e sancionadas pela coação internacional organizada.

O direito internacional existe, entretanto, como um conjunto de preceitos normativos que se fundamentam na consciência coletiva da solidariedade internacional e no sentimento de justiça que condena todos os atentados à solidariedade.

Vê-se, da exposição supra, em que procuramos traduzir com a maior fidelidade o pensamento de Duguit, qual o fundamento do direito internacional, segundo os princípios de sua teoria geral do direito.

\section{Crítica}

3. Duguit é considerado, hoje, como um dos mais altos e nobres expoentes da cultura jurídica franceza.

A originalidade de seu pensamento, a sinceridade de suas convicções filosóficas, a firmeza de seus princípios, a vastidão de sua cultura jurídica, a energia com que sustentou sua doutrina e o estilo ameno e elegante de seus escritos fizeram dêle um dos juristas mais lidos e discutidos na atualidade.

Ainda aquêles que divergem de sua doutrina, que não aceitam os princípios e fundamentos de sua teoria realista do direito objetivo - e são em maior número que os seus discípulos - são unânimes em reconhecer o merecimento invulgar do eminente publicista na sua luta apaixonada contra o arbitrário, sob a forma de direito subjetivo - um poder da vontade de se impôr às outras vontades - quer do indivíduo, como atributo da personalidade, quer do estado, como atributo da soberania. 
A preocupação constante de Duguit, em tôdas as suas obras, foi no sentido de demonstrar que as relações entre os homens, vivendo em sociedade, devem estar subordinadas à norma de direito objetivo, que é anterior e superior à vontade humana e surge espontâneamente da solidariedade e do sentimento coletivo de justiça e se impõe, por igual, a governantes e governados. Instaurar, em suma, o imperio do direito.

A sua teoria sôbre o fundamento do direito internacional teve a maior repercussão nos meios jurídicos.

Ao que informa o acatado mestre Nicola Politis - "Il n'est, aujourd'hui, ni cours ni ouvrage de droit international qui ne fasse de larges emprunts à cette doctrine, soit pour se couvrir de son autorité, soit pour la rectifier ou la contredire. Le nom de Duguit est parmi ceux qui sont le plus souvent cités dans le riche enseignement dont le droit international est depuis dix ans l'objet à l'Académie de la Haye. Dans le recueil des cours qui y sont professés, il n'est presque pas de volume où sa doctrine ne soit évoquée." (in "Archives de Philosophie du droit et de Sociologie Juridique", nrs. 1 e 2 , de 1932, pg. 70 ).

Todavia, essa teoria é, na verdade, passível dos mais sérios reparos, como tem sido acentuado por juristas da maior autoridade no campo do direito internacional.

Antes do mais, objetou-se que Duguit, desenvolvendo combate tão cerrado à noção do direito subjetivo, por considerá-la anti-cientifica e puramente metafísica, por ter a vontade como fundamento, quando, "para determinar em que consiste êste poder, esta qualidade, seria preciso conhecer, primeiro, a natureza intima da vontade humana, o que o homem não pode, nem poderá jamais, pois que há nela um elemento que escapa à sua percepcãa e à sua observação" ("Traité", vol. I, pg. 16), foi, entretanto, assentar na "consciência jurídica da massa dos indivíduos" o fundamento do direito internacional; e nada será mais metafísico que a conceituação do que seja "consciência jurídica" da "massa de indivíduos". 
Empregando o melhor de seu esfôrço por banir a metafísica do campo das investigações jurídicas, Duguit terminou, sem o perceber, por fazer pura metafísica a propósito do direito internacional.

Outro reparo, da maior procedência, feito por um insigne jurista, profundo conhecer desta disciplina jurídica, o afamado professor Louis Le Fur, é o de que Duguit não distinguiu, como cumpre fazê-lo, em se tratando da solidariedade como fonte do direito internacional, a bôa da má solidariedade, pois é inegável que ambas coexistem. Não se encontra na doutrina de Duguit o critério para se fazer essa distinção que é indispensável, eis que o direito internacional não pode surgir da solidariedade para o mal. (in "Recueil des Cours de l'Academie de La Haye", 1927, tome III, pgs. 263-439).

A crítica é irrespondivel. No panorama internacional contemporâneo verifica-se a existência de "solidariedade" entre a urss e os países sob sua ocupação, seus satélites na órbita universal. Solidariedade imposta pela fôrça, não importa, mas que repercute nas votações nas Assembléias da o.N.U. onde êsses países comparecem como nações livres e soberanas.

A solidariedade decorrente das relações entre êsses países e a unss pode dar origem a verdadeiras normas de direito internacional?

Dentro da pureza dos princípios da doutrina de Duguit, sim, porque não há nela qualquer distinção a fazer, qualquer qualificativo a se emprestar à solidariedade como puro fato social.

Todavia, como demonstrou o prof. Louis Le Fur, é mister aferir a solidariedade segundo um princípio moral.

À luz dêsse princípio, a solidariedade existente nas relações internacionais entre a urss e seus satélites, bem como a que fundamentou o chamado eixo Roma-BerlimTóquio, não gera verdadeiras normas de direito internacional por se tratar de uma solidariedade contrária à moral internacional - - não há direito contra a moral! 
Duguit faz um apêlo ao sentimento de justiça que se arraiga na massa das consciências individuais, como suporte jurídico da norma internacional.

Mas, que se deve entender por "massa" de indivíduos?

A simples maioria, dos regimes democráticos, nas eleições e nas votações? A unânimidade subserviente e domesticada do partido único nas ditaduras fascistas e bolchevistas?

O conceito de "massa dos espíritos" é impreciso e, portanto, imprestável para servir de base, em tese, às normas de direito internacional.

Como salientou o eminente mestre Braz Arruda, em suas memoráveis e brilhantes aulas de direito internacional, professadas no Curso de Doutorado, nesta gloriosa Faculdade, ao tratar do "consentimento comum", que: "saber si há, em determinado caso, consentimento comum é um fato de prática e não de teoria. É um caso de observação e apreciação, como a conhecida pergunta: quantos grãos fazem um monte?" (in "Revista da Faculdade de Direito de S. Paulo", 1938, vol. xxxiv fasc. II, pg. 530).

Assim, carece de valor ciêntífico o fundamento proposto por Duguit para o direito internacional.

$\mathrm{Na}$ verdade, como o demonstrou exaustivamente o professor Braz Arruda, o direito internacional funda-se na convicção profunda que os Estados têm de que se devem submeter às normas jurídicas em suas relações. Perguntar, porém, porque os Estados estão convencidos de que o direito internacional é obrigatório, investigar o motivo, a razão de ser dessa obrigatoriedade, é questão que não interessa ao estudo dessa disciplina; é um problema meta-jurídico. 